\title{
Complexity-Based Agile Enterprises: Putting Self-Organizing Emergence to Work
}

\author{
Lee Dyer \\ Jeff Ericksen
}

Working Paper 08 - 01 


\title{
Complexity-Based Agile Enterprises: Putting Self-Organizing Emergence to Work
}

\author{
Lee Dyer \\ ILR School \\ Cornell University \\ Ithaca, NY 14850 \\ \& \\ Jeff Ericksen \\ Institute of Labor and Industrial Relations \\ University of Illinois \\ Champaign, IL61820
}

January 2008

$\underline{\text { http://www.ilr.cornell.edu/cahrs }}$

This paper has not undergone formal review or approval of the faculty of the ILR School. It is intended to make results of Center research available to others interested in preliminary form to encourage discussion and suggestions.

Most (if not all) of the CAHRS Working Papers are available for reading at the Catherwood Library. For information on what's available link to the Cornell Library Catalog:

http://catalog.library.cornell.edu if you wish. 


\begin{abstract}
Organizations competing in hypercompetitive marketplaces have two possible paths to potential success. They can attempt to transform traditional bureaucracies into more nimble, adaptable, and resilient entities, which clearly is the path most traveled. Or they can try pathbreaking, which involves adopting a completely different organizational paradigm: the complexity-based agile enterprise (C-bAE). C-bAEs have no a priori hierarchies, no a priori organizational structures, and no a priori business strategies. They rely instead on ongoing interactions among self-organizing participants operating at the edge of chaos to form and reform, strategize and re-strategize on the fly. Does this work? We don't know for sure, although there is some solid theory and a little bit of evidence to suggest that it might - that under the proper conditions, these progressive dynamics may well engender a stream of novel and yet coherent products, services, and solutions capable of delivering a series of temporary competitive advantages and, thus, the possibility of long-term survival. This paper explores the promise, with particular emphasis on the process of mobilizing or creating the conditions that foster the constant co-creation of emergent organizational forms and innovative outputs.
\end{abstract}

Financial support for the preparation of this chapter was provided by the Center for Advanced Human Resource Studies (CAHRS), ILR School, Cornell University and by a grant accompanying The Michael R. Losey Human Resource Research Award accorded to the first author by the Society for Human Resource Management (SHRM) 


\section{Complexity-Based Agile Enterprises: Putting Self-Organizing Emergence to Work}

You are unlikely to see the future if you're standing in the mainstream.

Gary Hamel

Pathbreaking is a lot more rewarding than benchmarking

Gary Hamel \& C.K. Prahalad

We live in turbulent times. Many organizations currently operate, either by choice or chance, in a maelstrom of fickle customers, shifting markets, rapid-fire technological change, and obsolescing business models. Traditional notions of strategizing, organizing, and resource management, including human resource management, that have served so well for so long are increasingly being challenged. Accordingly, some firms that compete in dynamic marketplaces characterized by turmoil and frequent upheavals are on the lookout for new and more appropriate ways of doing business (e.g., Hamel and Valikangas, 2003; Hamel 2007). In general, their quests take one of two paths (as shown in Figure 1).

By far the most common (the left side of Figure 1) takes the bureaucratic model and its emphasis on sustained competitive advantage, hierarchy, continuity, stability, and discipline as given. And then from this base the approach explores ways to make the model more innovative (Christensen, 1997), dynamic (Peterson \& Mannix, 2003), adaptive (Haeckel, 1999), kinetic (Fradette \& Michaud, 1998), resilient (Hamel \& Valikangas, 2003), and so forth. The second path, far less-traveled (and illustrated by the right side of Figure 1), emanates from a different paradigm. It postulates that under conditions of hypercompetition and creative destruction, the best firms can hope for is to attain a series of temporary competitive advantages that, with luck, add up to long-term survival. It suggests, in turn, that temporary competitive advantages stem from continuous streams of leading edge products, services, and solutions which emanate from organizational milieus that emphasize innovation, dynamism, and adaptiveness blended with just enough stability and discipline to keep them from spinning out of control. 
Figure 1

Bureaucracy vs. Cas-Based Agile Enterprises

THE BUREAUCRATIC ORGANIZATION
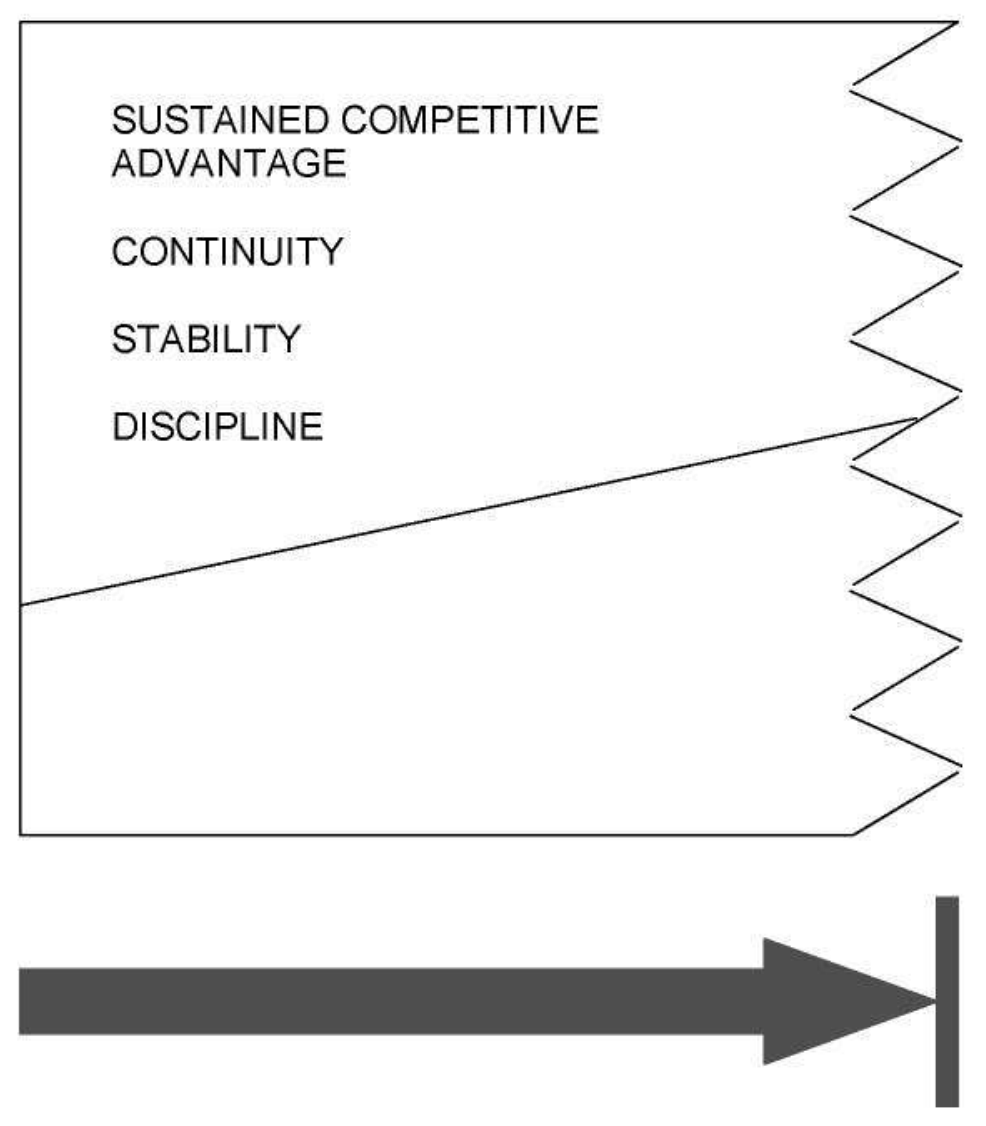

THE

CAS-BASED AGILE ENTERPRISE
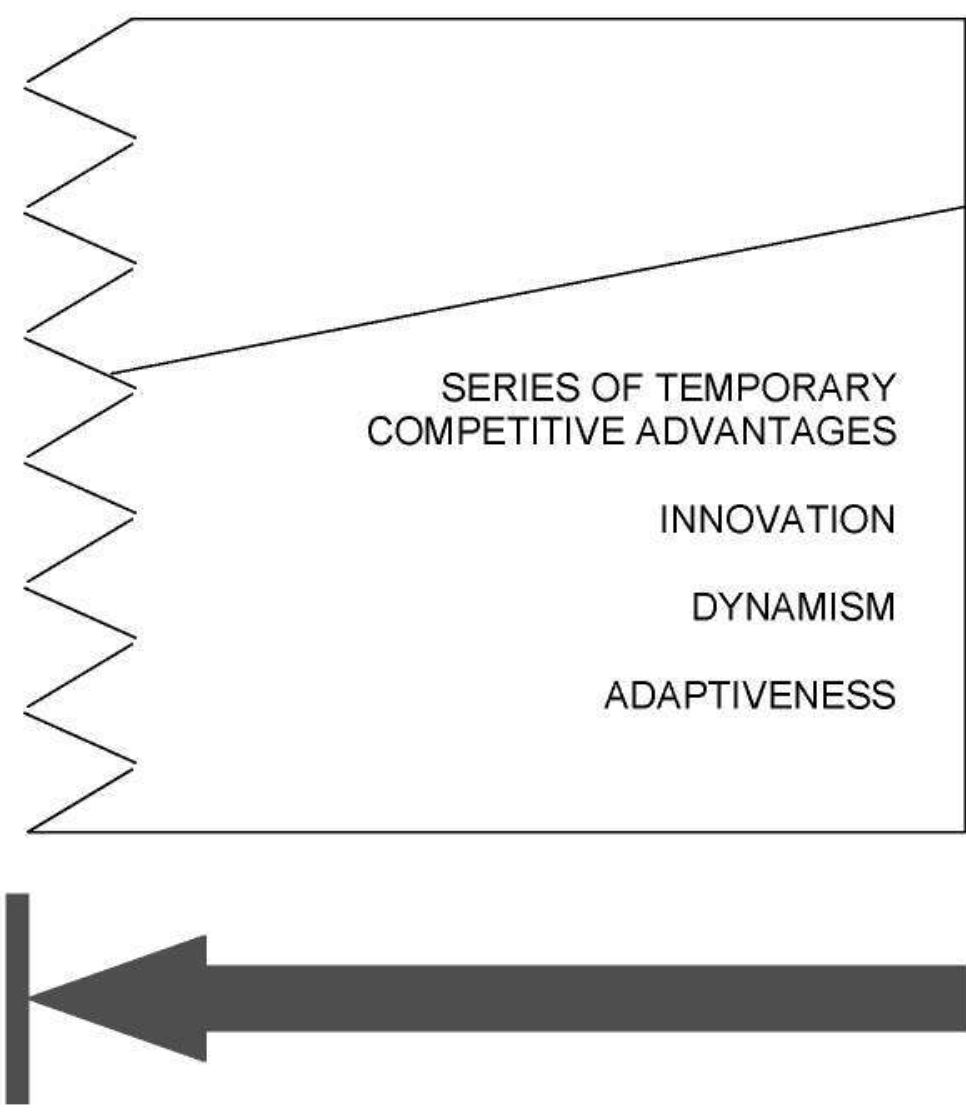
It might be thought that these two paths constitute a difference without a distinction and that eventually they would naturally converge. Given their fundamental differences, however, we are inclined to think otherwise, as the gap in the middle of Figure 1 indicates and our subsequent discussion illustrates.

We approach the analysis from the right-hand side of Figure 1 using concepts derived from complexity science (some say complexity sciences, since as Axelrod \& Cohen (1999: 15) note, "... there is little convergence among [complexity science] theorists ... it is not a field in which a crisp and unified theory has already been developed, nor is ... expected in the next few years"). Complexity science eased into the management and organization literatures in the U.S. during the 1990s. A few researchers and writers began viewing marketplaces and organizations as, or at least as analogous to, the complex adaptive systems (CASs) studied by biologists, chemists, and so on and thus conceptualizing and studying them as such (Anderson, 1999). Over time, this notion gained a fair amount of traction in some circles. It has its own journal: $E: C O$ (formerly Emergence, Complexity and Organization), now in its eighth year. At least 30 books of this genre had been published by the late 90 s (Maguire \& McKelvey, 1999), and many more have appeared since (e.g., Bennet \& Bennet, 2004; Fulmer, 2000; Hazy, Goldstein \& Lichtenstein, 2007; Lewin \& Regine, 2000; and Pascale, Millemann \& Goija, 2000). (For a comprehensive review of this literature, see Holbrook [2003])

Interestingly, much of this literature implicitly or explicitly accepts the fundamental precepts of the bureaucratic model - managerial control, hierarchy, and so forth - and, as a result, many of its prescriptions and exemplar organizations differ very little from those found in more conventional analyses. Thus, it offers very little that is new or thought-provoking for serious students of human resource management. Pascale et al (2000: 13) in their book Surfing the Edge of Chaos are particularly up front about this: "What we are advocating is appropriate use of tools of the old paradigm, incorporated in a new management repertoire". 
Some suggest that this amounts to little more than using CAS-based concepts to serve up old wine in old bottles using new labels (e.g., Stacey, Griffin \& Shaw, 2000).

So we take a different, more radical tack by exploring an approach to "harnessing complexity" (Axelrod \& Cohen, 1999) that we call Complexity-based Agile Enterprises (C-bAEs). This approach, we believe, has the potential to take full advantage of the insights that complexity science has to offer and to open up new avenues with respect to unleashing human initiative and creativity in organizations. Richardson (2005: 394) reminds us, however, that "Complexity 'thinking' is the art of maintaining the tension between pretending we know something and knowing that we know nothing for sure". Thus, our analysis is admittedly speculative. We lay no claim to having all the answers, or even to knowing all of the right questions. In the pages that follow, we initially explore a few key complexity science concepts and weave them into a framework that is then used to guide the remainder of our analysis, which focuses on three key organizational processes: strategizing, organizing, and mobilizing.

\section{Some Key Concepts From The Cas Literature}

Although the CAS-based literature is eclectic, from it we can extract six key concepts that are particularly relevant for our purposes: CASs, agents, interactions, self-organizing, edge of chaos, emergence, and emergent properties.

\section{Key Concepts}

CASs are commonly conceptualized as holistic structures composed of hierarchically nested levels, such as those shown in Figure 2. In biology, the structures might consist of subcomponents such as organisms, species, and ecosystems; in the business realm, participants, contexts, and marketplaces. The usual practice is to refer to a focal subcomponent as the CAS and the key actors as agents. When an ecosystem is the CAS, for example, species are the agents; when a species is the CAS, organisms are the agents; and so on. In general, whether in biology or business, the central issues include, first, how CASs of interest fit (or do not fit) within their larger structures and thus survive (or die) and, second, how this fit (or 
lack of fit) is enhanced (or diminished) by the agents' ongoing interactions with one another and with various artifacts (objects used by agents).

Figure 2

Complex Adaptive Systems-Hierarchically Nested Levels

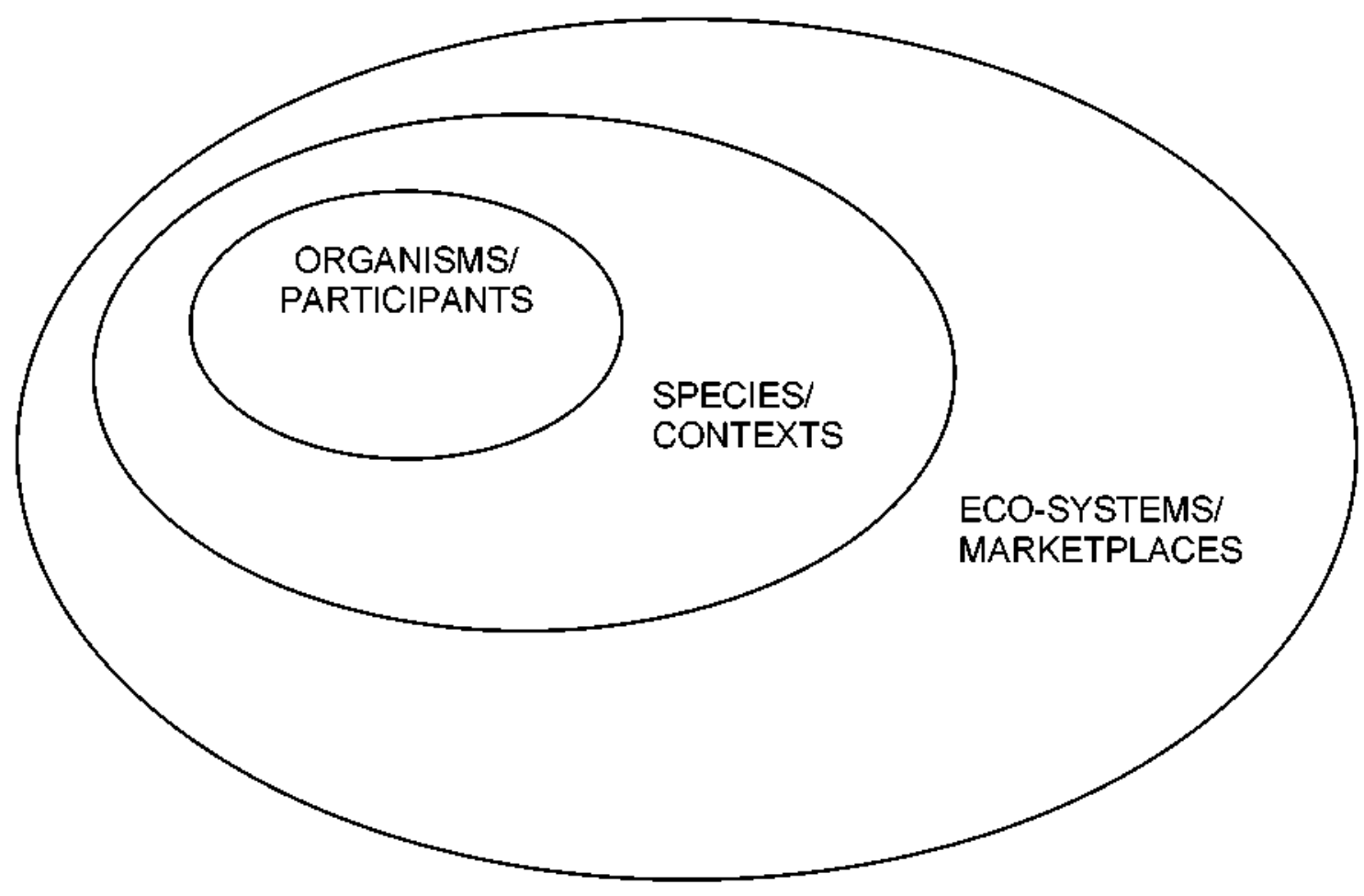

CASs co-evolve by means of self organizing. This is not the customary "... view of the autonomous [agent] first thinking and then choosing an action, but of [agents] in relationship[s] continuously evoking and provoking responses in each other, responses that each paradoxically selects and chooses" (Stacey et al, 2000: 172). Here is how the process works (Prigogine, 1997). Constant interactions among agents regularly amplify into bifurcations (essentially Y's in the road) where the agents are forced to make conscious or unconscious "choices". Feedback from these "choices" then sets off more interactions which create additional bifurcations and more "choices", and so forth and so on ad infinitum. And thus CASs evolve, or more precisely are co-evolved by self-organizing agents, over time. The process is akin to an un- 
choreographed, spontaneous dance "... that proceeds through a subtle interplay of competition and cooperation, creation and mutual adaptation" (Holbrook, 2003: 83). When it comes to selforganizing, as the term suggests, no one is in control and there is no grand plan or design. Whatever happens, happens.

Self-organizing works when CASs exist in a certain state, commonly and somewhat provocatively referred to as the edge of chaos, where the defining property is an ongoing dialectic between dynamism and stability, freedom and control. To grasp the essence of the edge of chaos, imagine a continuum with three states (Holbrook, 2003: 15). At the left is State 1 where stability or equilibrium reigns. In the middle is State II characterized by punctuated equilibrium. At the right is State III where chaos or disequilibrium reigns. Now, between States II and III, but edging over toward State III, insert State IV - the edge of chaos - where elements of disequilibrium and equilibrium are in constant interaction. This state (which despite the name is a state, not a precipice) is where self-organizing thrives. And fortunately, it is the state that self-organizing naturally tends to favor. Research in many realms (although alas not in work organizations) has shown that CASs drift towards State IV in the interest of survival (see Holbrook, 2003: 15-20). In States I or II, stability drives out dynamism, innovation is throttled, and momentum is lost to other, more adaptable CASs. In State III, the opposite occurs and CASs essentially spin out of control and self-destruct. In State IV, however, they capitalize on the forces of yin and yang, a flow of opposite, yet complementary energies and continue to coevolve.

Self-organizing at the edge of chaos engenders emergence, which can involve two types of outcomes - new forms of CASs and outputs. The beauty of emergence is that it tends to consist of outcomes imbued with two critical emergent properties: novelty (in the sense of being truly unique) and coherence. At one level, as CASs co-evolve they constantly emerge in new forms of dynamic processes and patterns. Often emergent forms are the outcomes of interest. But for firms, forms tell only part, albeit an important part, of the story. System outputs are also 
critical. Self-organizing at the edge of chaos tends to engender a stream of innovative, but also potentially viable, products, services and solutions (for explanations of how and why this occurs see Holbrook, 2003: $39-46$ and Storey et al, 2000, Chapter 6). And it is this ability that tends to separate winners from losers in dynamic marketplaces. This, then, is why we believe the CASbased approach has so much potential vis-à-vis flattened, decentralized, and streamlined bureaucracies.

But, of course, there are a couple of catches. CASs' outcomes typically display two additional and related emergent properties: unpredictability and uncertainty (Cilliers, 2005; Gershenson \& Heylighen, 2005). This is so for three interrelated reasons. First, CASs are very sensitive to what are (somewhat erroneously) called initial conditions; that is, they have histories that are constantly unfolding and, thus, the nature of any emergent outcome, which is fleeting and hard to pin down, has a major impact on the nature of the next emergent outcome, and so forth and so on ad infinitum. A slight twitch here and there and everything might well be different. Second, in CASs interactions among agents and the resulting feedback patterns are voluminous, rich, and non-linear and so can lead just about anywhere. Third, small perturbations in CASs sometimes reverberate into major changes (it is said, for example, that the fluttering of butterflies in Brazil can potentially unleash windstorms in Texas), while large ones are sometimes absorbed with barely a ripple.

Given this combination of circumstances - uncertain "initial conditions", tangled webs of untraceable interactions and feedback loops, and unknown perturbation patterns - it is hardly surprising that CASs reveal no simple cause and effect relationships. This, in turn, means that at any given time actual emergent outcomes - forms and outputs - are only a few of the many that could have occurred (Kurtz \& Snowden, 2003). Further, there is no guarantee that they will be valuable. As noted earlier (refer back to Figure 2), CASs are also agents embedded in larger CASs which, of course, are also self-organizing, so no particular outcome is assured a positive fate. In brief, self-organizing at the edge of chaos is capable of engendering all manner of 
outcomes and no one knows for sure what will emerge until the emergence occurs. And even then it is far from certain that anyone will like it (Storey et al, 2000: 152-154). This, of course, can be unnerving.

\section{CASs at Work}

Consider the tower-building termites of Africa and Australia (this account is adapted from Wheatley \& Kellner-Rogers, 1996: 68). Within their CASs, these agents instinctively form groups that are constantly in motion acting and reacting to what is going on around them, moving dirt around sometimes cooperatively and sometimes competitively in seemingly random fashion, conducting what in essence is a plethora of unplanned experiments. All on their own; as far as anyone knows there are no termite architects, designers, or straw bosses. No question, the termites go down plenty of blind alleys and make a fair share of mistakes, but when things come together the results are immense towers (the largest in the world relative to the size of their builders) that are engineering marvels filled with specialized chambers, perfectly formed arches and tunnels, and even air-conditioning systems. This is self-organizing emergence at work.

Or consider the case of Linux (Axelrod \& Cohen, 1999: 52-58; lannacci, 2005). This well-known computer operating system is the product of ongoing interactions among a constantly evolving cadre of volunteers (agents) located around the globe. No one actively recruits these techies or does anything special to keep them in the fold; they come and go as they please. No one tells them what to do or how to do it either. They collaborate with whom they choose, for as long as they choose, and how they choose. Virtual teams form and re-form all the time. This turmoil engenders some useless code, but also a fair amount that is truly innovative and even elegant (a group of senior engineers, called "system maintainers", ultimately determines what code does and does not make it into official Linux releases, but this group has no direct control over the process). So far, somewhat against the odds, Linux's approach to so-called open source software development has been immensely successful, 
churning out versions of an operating system that have become increasingly formidable challengers to the hegemony of Microsoft's Windows, as well as other proprietary systems. This is also self-organizing emergence at work.

As these examples suggest, in CASs and by extension C-bAEs self-organizing emergence is a two-edged sword. On the one hand, it has the power to engender emergent outcomes that are on the cutting edge of imagination and innovation. On the other hand, it forces an explicit recognition of the fact that creativity and uncertainty are opposite sides of the same coin. To potentially reap the benefits it is essential to learn to live with life at the edge of chaos, with constant change, and with inherent unpredictability. CASs eschew the familiar trappings of traditional organizations in hopes of unleashing the full range of their distributed intelligence. They are heterarchies with no a priori pecking orders. No one gets to stand aloof or aside and decide. If any agents or groups of agents (executives, say, or human resource managers) presume to provide blueprints to guide self-organizing, then it is not self organizing. And if they attempt to dictate what should emerge, then it is not emergence (Stacey et al, 2000: 145).

\section{Strategizing and Organizing}

The termite and Linux examples suggest that in C-bAEs self-organizing is likely to focus, in part, on two highly interconnected processes and their emergent outcomes. One is strategizing, which engenders (sometimes novel, coherent, and salient) outputs such as products, services, and solutions. The other is organizing, by which participants unfold ongoing variations in their organizational forms and dynamics - evolving patchworks of connections, collaborations, and work arrangements. A discussion of these processes and potential outcomes follows.

\section{Strategizing: Co-Evolving Emergent Outputs}

In the CAS-based literature, analogies are often drawn between biological eco-systems and marketplaces, only in the former instance species are the agents, while in the latter case 
products, services, and solutions are (Peltoniemi, 2006). The fitness landscape is a commonly used metaphor in both analyses (Kaufmann, 1995). Fitness landscapes consist of many constantly evolving peaks and valleys. Peaks represent points of fitness with high potential payoffs, while valleys represent depths of unfitness with no potential payoffs. Since fitness landscapes are CASs, they are self-organizing - that is, it is ongoing interactions among agents (e.g., competing products) that engender the endless ebbing and flowing of peaks and valleys. In this view, then, marketplaces are treated not as external entities with known or estimable opportunities and threats, but rather as encapsulating places in which agents are enveloped by unknown and unpredictable patterns of opportunities and threats that come and go. To be sure, products, services, and solutions are in pursuit of their own advantages, but they do not determine their own fates. In the end, success or failure depends on the cumulative effects of the many interactions that occur, over which there may be some leverage but certainly no control.

Fitness landscapes take many forms. Some are quite smooth (characterized by periodic change) and some are tumultuous (characterized by constant change). Between these extremes are so-called rugged landscapes (characterized by considerable, but not constant change). Landscapes are considered rugged if they sometimes contain fairly high peaks that last a while before they collapse. In marketplaces, fairly high peaks are created by products, services, or solutions that find willing customers or clients and sell well for a while. Sometimes products, services, and solutions create high peaks virtually unmolested. More often, though, when they head up what appear to be potentially high peaks, competitors or government agencies, or some other agents counter and if they are successful the peaks cap out at relatively low levels or even evaporate. If these counter-moves are weak, however, the peaks continue to grow and achieve some measure of stability, allowing the extraction of revenues. Eventually, jousting among agents (e.g., tough negotiations with customers or clients) puts peaks on shaky ground. Counter-moves may create temporary sanctuaries, but sooner or later 
these efforts become futile and peaks are abandoned so that resources are freed for other, more promising pursuits. Overall, then, rugged landscapes are dynamic equilibriums consisting of inherent and ubiquitous tensions that drive constant change coupled with occasional stability.

C-bAEs engender rugged landscapes. Ongoing, real-time interactions among organizational participants form strategies - choices about where, with what, and how to compete on rugged landscapes. Products, services, or solutions emerge as participants muck about in marketplaces searching for or trying to sustain or abandoning peaks, while trying to avoid languishing in valleys. Rather than dwelling on things as they would like them to be (i.e., ideal states), participants start with things the way they are and then move forward. They create and experiment with options to see what works, and adapt quickly to capitalize on emerging opportunities and avert impending disasters, and in the process incrementally co-create (with other agents) uncertain futures (Kawai, 2005; Snowden, 2006). This mucking about on rugged landscapes is in lieu of conducting formal strategic planning processes which, of course, are pointless exercises in marketplaces fraught with multiple plausible paths and players all destined for indeterminate places (Chelariu, Johnston \& Young, 2002 [cited in Holbrook, 2003]; Carlisle \& McMillan, 2006).

Thus, in C-bAEs, every venture is in perpetual beta mode (McGrath \& Keil, 2007; Tapscott \& Williams, 2006: 256-257). Stewart (2007) puts it this way:

The voyage is unclear. Success comes to those who read the unobvious but critical complications of wind and current, who exploit every puff in the doldrums, who seize the chance for a long run downwind, who tack tirelessly in the fact of adversity, and who abandon the sail when conditions are not right.

More formally, in C-bAEs, participants are called upon to nurture endless streams of ventures potential and actual products, services, or solutions - through strategic cycles consisting of as many as four phases: exploration, exploitation, adaptation, and exit (see Figure 3).

In exploration, participants conduct low-cost, discovery-driven probes into marketplaces to test ideas and develop prototypes, capture and analyze signs of potential, and quickly make 
educated guesses about which ventures are and are not worthy of pursuit (Brown \& Eisenhardt, 1997; McGrath \& Boisot, 2005; Pisano, 1994). They then move promising ventures on to exploitation, where they do their best to capitalize on competitive advantages and thus generate revenues. Since stuff happens on rugged landscapes, participants also exercise an instinctive, almost automatic ability to sense potential complications early, assess their significance swiftly and accurately, and adapt accordingly (Lewin \& Volberda, 1999). Notwithstanding, they also know that on rugged landscapes no peaks last forever, so exit is inevitable. When the time seems right, they do not hesitate to abandon marginal ideas or even to cannibalize existing marketplace offerings when they have run their courses (Foster \& Kaplan, 2001; Horn, Lovallo \& Viguerie, 2006).

How do we know that this type of strategizing will generate enough sufficiently novel and yet coherent outputs to provide firms with at least reasonable chances of attaining periodic advantages on rugged landscapes? The short answer is: We don't for sure. But the CASbased perspective suggests that it may. The well-spring here is creativity - the constant generation of new, novel, and potentially useful ideas - and this is what ongoing interactions among savvy participants tend to do. Bennet and Bennet (2004: 115) explain it this way:

"Teams and communities ... facilitate ... creativity. Ideas are probed through the dialogues of teams and the virtual interactions of communities, placed in incubation as knowledge workers intermingle these exchanges with actions. Illumination occurs in many forms, possibly by several members of the team or community, and as it is shared offers the potential for quick verification and validation, as well as the opportunity for additional probing leading to additional new ideas. These ideas are the mental implements used to gain competitive advantage. Since ideas build upon ideas, the more these implements are used, the more ideas available for use, and the more opportunity for the organization to develop and fulfill its own unique competitive advantage.

From the well-spring of creativity springs innovation - the process of transforming a wealth of potentially useful ideas into streams of unique and coherent outputs (products, services, and solutions). The type of strategizing we describe has the potential to do this for a number of reasons. First, C-bAE participants are perpetually close to the action which makes 
them particularly knowledgeable about marketplace dynamics and enhances both the efficacy and timeliness of the strategic moves they initiate. Experiments at Hewlett-Packard and Eli Lilly, for example, have shown that participants on the ground are superior to highly trained professionals when it comes to discerning dynamic market movements (Surowiecki, 2004: 221). Second, participants process marketplace intelligence and make choices about resource allocations on the spot and rapidly, free of the organizational labyrinths and layers that bind more traditional firms (Christensen, 1997), thus facilitating transitions among the four phases of the strategic cycle (exploration, exploitation, adaptation, and exit). Third, participants become used to constant change, thus reducing the trauma and resulting friction that otherwise might result from ongoing rounds of creation and destruction.

Theoretically, at least. As noted, there are no assurances that things will work out this way. There is always the chance that marketplace dynamics and/or internal self-organizing will degenerate into stasis thus engendering insufficient creativity and innovation to locate, climb, and temporarily sustain high peaks on rugged landscapes. Or that one or both will spin totally out of control and into chaos. Whether or not these things occur depends, in part, on what happens when C-bAE participants co-evolve emergent forms - a process we call organizing.

\section{Organizing: Co-Evolving Emergent Forms}

Clearly, C-bAEs have no predetermined or permanent organizational structures - no a priori or fixed hierarchies, or departments, or line and staff differentiations (which of course includes human resource functions). Rather, self-organizing at the edge of chaos engender a variety of organizational forms over time depending on the many "choices" participants make at various bifurcation points. In other words, organizing is analogous to and in fact constantly interacts with strategizing. So, the rugged landscape metaphor applies here as well. In organizing, interactions among participants create various organizational arrangements that those involved hope will scale fitness peaks (i.e., have the capacity to nurture ventures into more advantageous positions). When this appears to be happening, the arrangements are 
pursued; when not, they are altered or abandoned. This means that organizational forms, like ventures, are in perpetual beta mode and also constantly traversing cycles of exploration, exploitation, adaptation, and exit. While prediction is impossible, we can speculate that, in general, the prevailing organizational arrangements in C-bAEs will consist of numerous, continuously evolving teams.

Figure 3 illustrates the process. A snapshot at Time 1 shows that this fictitious C-bAE was pursuing eight ventures through various points on the strategic cycle. To this end, its 50 participants had formed nine teams involving some 70 roles (some participants were on multiple teams). By Time 2, the firm was again pursuing eight ventures, although four of the originals were gone and four new ones had formed - and three of the four originals had moved to different points on the strategic cycle. At this point there were 40 participants who had organized themselves into nine teams involving 61 roles (10 of the original 50 participants had removed themselves from the strategic cycle, although not necessarily from the firm). Snapshots taken at Times 3, 4, and so on would, of course, show quite different patterns of ventures, teams, and participants. Further, a more finely-grained look at the team level would reveal participants maneuvering to meet new challenges by incessantly altering team structures and processes as well as their own activities and roles.

These are ongoing dynamics. Nonetheless, as teams coalesce around ventures, especially during exploitation, they usually settle down (i.e., toggle back toward stability end of the edge of chaos zone) at least temporarily. Participants consensually establish semipermanent working relationships, which can involve temporary hierarchies consisting of coordinators (such as the "system maintainers" at Linux), team leaders, sub-team leaders, and the like, as well as boundary conditions, goals, priorities, deadlines, and rules of engagement. But - and this is the important point - these relationships, roles, boundary conditions, and so forth are not chiseled in stone and are usually subject to revocation when teams disband (Kawai, 2005). 
Figure 3

Strategizing-Organizing Ventures and Teams

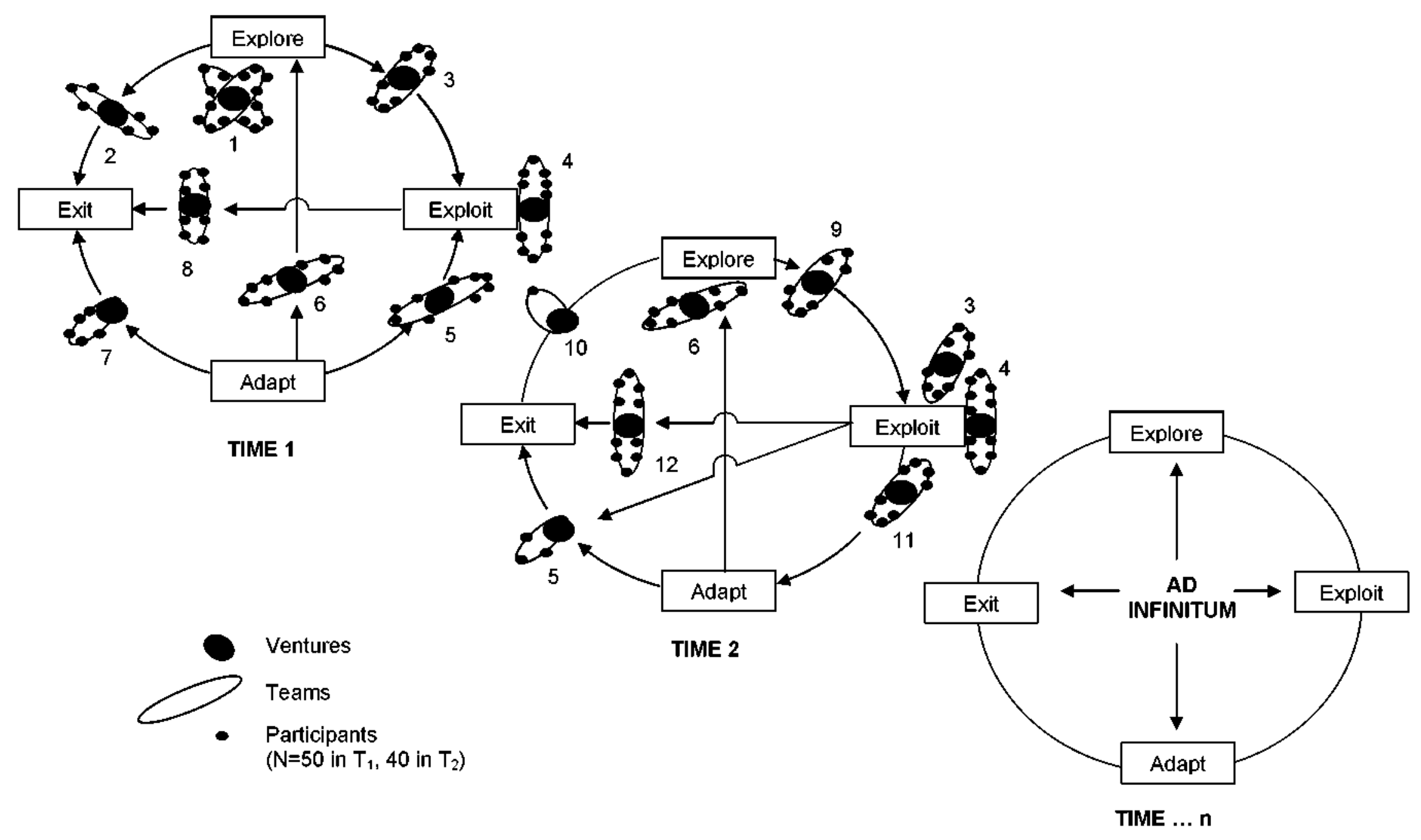


Not uncommonly, C-bAE participants form organizational infrastructures consisting of artifacts through which work is done. Examples might be core business processes, workplace designs, and information technologies (Axelrod \& Cohen, 1999). These tend to be relatively permanent, so it is important that they be designed in ways that promote rather than restrict participant interactions and facilitate rather than restrict self-organizing. Obviously, this is an important issue, but since it is also largely unexplored at this point we offer just a few preliminary thoughts on the way things may go.

Consider core business processes, which govern recurring patterns of interactions among participants, are essential features of organizational life. They are both broad-based (e.g., budgeting) and more focused (e.g., procedures for conducting experiments during exploration or guidelines for service delivery during exploitation (Axelrod \& Cohen, 1999: 113114). Fortunately, as researchers have come to realize, both types are inherent dualities that, when properly designed, serve as much to liberate behavior as to restrict it (Feldman \& Pentland, 2003). Generally, then, for C-bAEs the guiding principle is to favor protocols over standard operating procedures. Protocols leave ample space for participants to toggle between innovative and routine behaviors as situations require, while standard operating procedures impose hard-and-fast constraints and thus are best confined to circumstances where they cannot be avoided (e.g., to assure legal compliance).

The same general principle applies when participants are designing workplaces. First, units should be kept small. When they have more than 150-200 people, the evidence suggests, meaningful interactions among participants tend to decline precipitously (Gladwell, 2000: 175192). Second, within facilities, fixed gives way to flexible. Becker and Sims (2001), for example, advocate an "integrated portfolio strategy" that incorporates modular buildings, open spaces with easily movable panels in place of walls, nomadic plug-and-play work stations, and easily assembled and thus transportable furniture. This eliminates artificial barriers and makes it easy for C-bAE participants to co-create their own temporary work spaces on an as-needed 
basis (see also Conlin, 2006; Joroff \& Bell, 2001). This may well become less of an issue over time, though, as C-bAE participants increasingly work virtually. Beyond some tipping point, it may be that physical locations become little more than pared down, often leased drop-in centers. Or perhaps even passé. Socialtext, a small quasi-C-bAE, for instance, operates entirely with no physical facilities at all (Tapscott and Williams, 2006: 251-253).

C-bAEs inevitably employ cutting-edge technologies. Irrespective of specific applications, however, systems should be designed to unfailingly foster participant interactions and self-organizing. In C-bAEs it is critical that what one participant knows, all have easy access to on a real-time basis. This, in turn, implies the adoption of distributed and open information systems where the input, manipulation, and retrieval of information is a snap and only minimally restricted (e.g., for legal reasons). It also implies the widespread use of what Tapscott and Williams (2006: 11) call "weapons of mass collaboration". These include Internetand intranet-based wikis, blogs, and the like that facilitate hookups between projects and potential contributors and, once the two are connected, make it easy for participants to share knowledge and engage with each other on a peer-to-peer basis wherever they may be, just as participants in open source ecosystems do. Wikis, in particular, facilitate self-organizing. As Ross Mayfield, founder of Socialtext puts it, "Wikis hand control over to users to create their own way of organizing knowledge, workplaces, processes, and perhaps even their own applications in ways they've not been able to do before." (quoted in Tapscott \& Williams, 2006: 255).

In sum, then, C-bAEs begin their organizational lives tabulae rasae. Complexity science suggest that ongoing interactions among self-organizing participants, if the system sustains the edge of chaos, will engender an ongoing series of truly novel and yet coherent organizational configurations - forms and infrastructures. The precise nature of these, of course, remains to be seen, although we can be quite sure that at various times the forms will incorporate elements of stability - hierarchies, goals, priorities, and the like - as well as semi-permanent artifacts such as protocols, maneuverable work spaces, and cutting-edge technologies to facilitate the 
flow of work. Naturally, the hope and indeed the expectation is that the unfurling patterns will more often facilitate than hamper the strategizing process and, thus promote firm survival. But, as always, there are no guarantees.

\section{Mobilizing}

In nature, the strategizing-organizing nexus is pretty much the whole story. Towerbuilding termites, as far as we know, work with whatever resources nature provides. C-bAEs could do pretty much the same, although when it comes to "harnessing complexity" there are good reasons to believe that this might not be the best way to go (Axelrod \& Cohen, 1999: Chapter 2). Unlike termites, human beings are prone to making conscious choices about resources. And obviously people differ when it comes to the attributes that make them more or less suited to thriving in hyperactive social communities where they are constantly called upon to co-create their own futures. It is likely, then, that C-bAE participants not only will, but also should constantly strive to create conditions that might enhance their organizing and strategizing activities.

We call this process mobilizing. Once again, it involves participants self-organizing at the edge of chaos - this time in efforts to emerge novel, coherent, and salient combinations of participant attributes (which means, in effect, turning the process back onto themselves). Again, the rugged landscape metaphor applies. Sometimes participants pursue configurations that cocreate fitness peaks (i.e., that enhance organizing and strategizing) and thus are retained for a while. Other times they run into obstacles and their efforts are adapted or discontinued. In other words, in C-bAEs participant configurations, like organizational configurations and ventures, are in perpetual beta mode, once again constantly traversing cycles of exploration, exploitation, adaptation, and exit.

Mobilizing is in large part analogous to human resource strategizing. It is aimed at getting the right numbers of the right types of participants in the right places at the right times doing the right things right - where right is defined as contributing to successful organizing and 
strategizing. Students of human resource strategy will recognize this concept as vertical fit or alignment (Dyer \& Ericksen, 2007). But there is a unique twist here. In traditional firms, business strategies and structures are expected to endure for some time so vertical alignment is viewed as a relatively static state. In C-bAEs, however, organizing and strategizing are dynamic processes that center on ventures, which means that vertical alignments (plural) are constantly emerging moving targets. In these firms, then, thoughts of creating enduring vertical alignments give way to efforts aimed at enhancing the likelihood of attaining an ongoing series of temporary vertical alignments. And this, we postulate, requires participant scalability (Dyer \& Ericksen, 2007).

Participant scalability emanates from two factors: calibrations and fluidity. The former refers to participants' collective capacity to ascertain what needs to be done to promote effective organizing and strategizing. The latter refers to participants' collective capacity to move themselves from where they are to where they need to be and/or to shift from less important and less effective behaviors to more important and more effective behaviors - and to do efficaciously and in timely, rapid, and cost effective ways (Dyer \& Ericksen, 2007; Hamel \& Valikangas, 2003). Participants who have mastered calibrations sniff out potential opportunities with recurring fidelity, while those who exhibit fluidity pounce on the most promising of these opportunities with alacrity. Calibrations without fluidity mean many lost chances, while fluidity without calibrations mean a lot of wasted motion. So we suspect that C-bAEs need both. But it cannot be said that these are necessarily sufficient conditions for success, given the inherent uncertainties involved.

So, how do C-bAE participants go about enhancing their own scalability? Here we speculate on a few things that might help, dividing them into two categories: shared mindsets and participant attributes. 


\section{Coevolving Shared Mindsets}

For C-bAEs, shared mindsets - configurations of visions, values, and the like - serve as relatively stable navigational beacons. Long staples in the traditional management literature (e.g., Ulrich \& Lake, 1990), shared mindsets are, we believe, even more essential for firms embroiled in constant change. Not everyone agrees, though. Stacey (1996: 15), for example, flatly states that any attempt by C-bAEs to "... inspire [participants] to follow some common vision, share the same culture, and pull together is to remove the mess that is the very raw material of creativity". In his view, however, shared mindsets are constraints imposed by managers (or others). We, on the other hand, assume that they can just as easily be liberating factors developed by the participants themselves.

Recall Linux's far-flung, ever-shifting cadre of volunteers. They embrace a shared mindset that incorporates both ends and means. There is a common purpose - "To best the beast from Redmond" - as well as a few generally accepted operating norms - e.g., openness, irreversibility, and visibility (Axelrod \& Cohen, 1999: 52-58; Iannacci, 2005). None of these were mandated. They were adopted and are accepted because the Linux volunteers perceive that on balance they do more to foster than inhibit "... the mess that is the very raw material of creativity". We see no reason why other C-bAE's participants would see things differently.

Shared purposes articulate the collective hopes of participants. Stated in fairly general and aspirational terms, they actually encourage the exercise of discretion. "To best the beast from Redmond" and Google's "To organize the world's information" are attractive ideas to many folks. They rally the troops in ways that expand horizons by reflecting lofty ambitions and everrising bars (the beast and the world's information keep moving on). But they also serve to keep expanded horizons from becoming infinite, especially if they refrain from dictating what participants should do and instead help to clarify what they probably ought not pursue (Linux and Google's participants are surely not working on the next big thing in, say, barbeques). Further, as participants deploy and perform they need some way to use the feedback that is 
constantly rolling in. Do their efforts and outputs seem to be more or less directionally correct? Are they mobilizing efficaciously and in timely, rapid, and cost-effective ways? To decide, it obviously helps to have a pretty good idea of where they are trying to go.

Shared operating norms define how participants behave with one another. In C-bAEs they essentially replace bureaucratic webs of rules and controls as guides to decision-making. While we cannot specify what any particular C-bAE's norms should be - that is up to the participants themselves - we can say for sure that it takes more than simply stating them to make them real. Ultimately, what counts is what is lived and reinforced by each and every participant each and every day. This is true in all organizations, but especially so in C-bAEs where prevailing norms are likely to be quite different from those participants have previously internalized from their experiences in traditional firms. We see this frequently in classroom simulations. Students usually put considerable time and effort into deriving and communicating a set of seemingly appropriate operating norms. Yet they typically find that it takes several weeks and often some (sometimes painful) violations before they truly begin to embrace the new ways (e.g., by openly sharing information), while shucking behavior derived from preconceived notions of how classrooms "really" work (e.g., the hoarding of information). And a few never quite get there.

In sum, co-evolving shared mindsets around a novel paradigm is certainly a difficult process that has to be done with care to avoid becoming the fool's errand that Stacey makes it out to be. But we know from the research of Argyris and Schon (1978) and others that mental models drive a lot of behavior. Absent appropriate shared purposes and operating norms, we believe, C-bAE participants lack navigational beacons on which to base their calibrations and the behavioral consistencies that foster the high level of trust on which fluidity ultimately depends. 


\section{Co-Evolving Participant Populations}

In C-bAEs, participants collectively decide who joins and, to some extent, who stays and goes, while also exerting influence over what is done by whom when. That is, they are the arbiters of their firm's human and social capital (Nahapiet \& Ghoshal (1998). And it takes rich stocks of both to sustain quality calibrations and fluidity on an ongoing basis. (These days, we realize, relevant stocks of human and social capital extend well beyond organizational boundaries - see, for example, Tapscott \& Williams [2006] - but that issue requires a fuller exposition than is possible here.)

Again, some might contend that C-bAEs' participants need not pay particular attention to enhancing stocks of human and social capital since both will automatically improve with experience. In the CAS-based literature, this is known as crossover, the process by which species are regularly improved as genetic contributions from parents are constantly recombined (Axelrod \& Cohen, 1999: 41-42). Generally, it seems reasonable to expect that the more participants interact the better they get at it - up to the point of saturation anyway (McFadyen \& Cannella, 2004). We contend, however, that while crossover is inevitable and essential, it is also insufficient and thus, once again, there is no good reason for C-bAEs simply to let nature take its course. Instead, there are a number of things participants might do to develop human capital without damaging social capital, to enhance social capital without diminishing human capital, or preferably to enrich both in one fell swoop. We consider these possibilities in four categories: staffing, development, rewards, and work load (note that this takes us into realms that in more traditional organizations would be considered the bailiwick of human resource organizations and professionals)..

\section{Staffing}

A major way that CASs evolve is through the creation, transformation, and destruction of agents (Axelrod \& Cohen, 1999: 38-61). This suggests the need for C-bAE participants to give 
careful consideration to the ways in which they collectively flow in, through, and out of their firms.

Participant Inflows. Initially, C-bAEs need to generate qualified applicants. This is no slam-dunk. Given the pervasiveness of the bureaucratic paradigm, it is unlikely that a large number of qualified applicants even exist. Not everyone, as Lebaron (1999) reminds us, is particularly eager to live at the edge of chaos. Research (as well as our classroom simulation experiences) bears him out. In a recent survey of 2,000 knowledge workers in 32 countries, for example, only about 25 percent of the respondents could reasonably be classified as "agile performers" (DiRomualdo \& Winter, 2005). One partial solution here might lie with the increasingly popular on-demand recruiting services (ODRSs) (Frase-Blunt, 2003). On the demand side, ODRSs, unlike contingency search firms, contract with clients for extended periods of time and come to know their needs well. On the supply side, they specialize by industry or competencies so they should be able to find and reliably ferret out potential agile performers quickly and easily.

Of course, C-bAEs' participants still retain responsibility for making final hiring decisions. They are looking for applicants who will likely enhance both human and social capital. One set of essential competencies pertains to technical knowledge and skills in areas such the dynamics of marketplaces and technologies under-girding potential and current products, services, and solutions. Here the emphasis would be on divergence; that is, on finding applicants who collectively possess strong foundational aptitudes and/or a breadth of well-developed competencies and thus have the potential not only to see the full range of potential calibrations, but also to demonstrate fluidity by deploying and contributing across a wide range of assignments and tasks (Wright \& Snell, 1998). But as much as divergence, or variation, is emphasized in the CAS-based literature (e.g., Axelrod \& Coher, 1999: 32-58), convergence is essential with respect to other competencies and attributes. That is, C-bAEs are likely to seek participants who individually top the scales and collectively display minimum variance on 
competencies such as creativity, interpersonal capabilities, and teaming skills (Morgeson, Reider \& Campion, 2005) and attributes such as a tolerance for ambiguity and a predisposition toward and comfort with constant change, which research suggests emanate from inherent personality traits such as proactivity, adaptivity, and resilience (Baterman \& Crant, 1993; Sherehiy, Karwowski \& Layer, 2007). Consider Google's vaunted hiring process. It "... values nonconformity nearly as highly as genius [and gives] preference ... to candidates who have weird avocations and out-of-the-ordinary experiences" (Hamel, 2006: A16). According to the company's Web site (www.Google.com), "Googlers range from former neurosurgeons, CEOs, and U.S. puzzle champions to alligator wrestlers and former marines ..." While this seems to work for Google, obviously a great deal of research remains to be done before we know whether hiring for divergence on the technical side and convergence on the cultural side really serves to enhance calibrations and fluidity in C-bAEs.

Participant Throughflows. When it comes to throughflows, C-bAEs encounter a dilemma. Fostering divergence encourages the use of throughflows to enhance participant development by broadening exposure to a variety of ventures. Godin (2000), for example, urges organizations in rapidly changing situations to embrace the notion of serial incompetence - a willing, even eager acceptance of the risks associated with bouts of temporary incompetence as the inevitable price of ongoing development. What firms need, he contends, are "... folks who are quick enough to master a task and restless enough to try something new [as soon as they have]" (Godin, 2000: 234). But obviously this can be overdone. Carried to its logical extreme, it would require C-bAEs to modify the pursuit of temporary vertical alignments, which require that participants take on assignments and tasks for which they are already wellequipped (Wright \& Snell, 1998). Clearly, there is no one right answer here so a lot of experimentation (including perhaps some computer modeling) will be necessary to uncover even conditional accommodations to this apparent conundrum. 
Participant Outflows. It might be thought that to preserve human and social capital, CbAEs participants should encourage long-term employment relationships, absent of course any thoughts of guarantees. But in non-growth situations, it may be necessary (even with the advent of serial incompetence) to encourage some involuntary turnover to open the door for new blood. Further, there will always be selection errors that have to be rectified. And finally, C-bAEs are at least as vulnerable as other organizations to tectonic shifts that lead to overstaffing and/or competency misalignments that do not yield to timely, rapid, and cost effective internal corrections. The danger here is that these essential adaptations will be excessively delayed and/or handled badly once they are addressed. How, then, to make them happen in real time? And well?

In C-bAEs, true incompetents, as well as malingerers and free-riders really stand out. But this does not mean they are easy to deal with. In classroom simulations, for example, we have found that while rare, such cases usually remain unaddressed unless and until they become flagrant and problematic. Absent a strong sharing of the C-bAE' common purpose, student participants tend to favor congeniality and harmony over confrontation. When serious cases are allowed to fester, the generalized negative effects on human capital (motivation) and social capital (cooperation and trust) are palpable. When such situations are confronted, improvements tend to be almost immediate and equally apparent - and especially so when it is perceived that justice was done. In our view, C-bAEs can benefit from these experiences. First, in problem cases, procrastination probably can be precluded if there is a strong sense of shared purpose, as well as a generalized norm of constructive confrontation. Second, and not surprisingly, the fairer the processes and outcomes, the better the results for all concerned. This suggests that it might be wise for C-bAE participants to form and invest resources in training standing teams (preferably with rotating memberships) that have authority to investigate problems, implement corrective measures, and, when warranted, mete out sanctions. 
In the event of tectonic shifts, an applicable model might be a variant of AES Corporation's compensation process (described in Table 1 and discussed below). As warning signs accumulate, participants would form small teams of respected colleagues to look at the facts, recommend courses of action, and widely disseminate all relevant information. If the teams decide that the best solution (or only feasible option) is layoffs, they would set goals and solicit self-nominations. These would then circulate for a period of open discussion (redundant non-volunteers would be encouraged to pony up, while valuable non-redundant volunteers would be encouraged to stay). Ultimately, the original teams would decide who would be granted packages to leave (the process could be repeated as necessary until the goal was reached). Undoubtedly, this would work only if severance pay and perks were generous and quality outplacement assistance was part of the package. If a process of this sort were successful in rebalancing human capital, it should also go a long way toward sustaining social capital since research has consistently shown that the morale of layoff survivors is enhanced if they perceive that their departing colleagues got a good deal (Brockner, Konovsky, CooperSchneider, Folger, Martin \& Bies (1994); Naumann, Bies \& Martin, 1995). When all is said and done, however, it is our guess is that the challenge of dealing with involuntary participant outflows on a timely, rapid, and cost-effective basis will be a major stumbling block for many $\mathrm{C}$ bAEs.

The preceding discussion assumes C-bAEs should be staffed at least in large part with regular rather than temporary participants. But is this the best way to go? Rousseau \& Arthur (1999: 9) say no, "In highly dynamic business environments, ... maximum flexibility through free agency is the employment strategy of choice". There is no question that their approach enhances external fluidity by making it relatively easy for participants to join and leave on a timely basis, usually rapidly and sometimes relatively cheaply (Matusik \& Hill, 1998). And it is the way that open source systems such as Linux operate. We wonder, however, if it doesn't also incur a high price with respect to both human and social capital. It means that many, if not 
most, participants may be new to the enterprise and thus lacking in firm-specific knowledge and also that they are essentially strangers who lack any meaningful interactive experiences with one another (Leanna \& Van Buren, 1999). To what extent, if at all, do these factors inhibit the quality of both calibrations and internal fluidity to the point where the benefits of external fluidity are neutralized? Once again, the answer to this question is likely situational. So it falls to CbAE participants to experiment with various mixes of regular and temporary participants over time in search of blends that appear to work under various sets of circumstances.

\section{Development}

Assuming quality staffing, the concept of serial incompetence presupposes continuous participant development. To some extent, as noted earlier, this occurs naturally. But the hectic pace of C-bAEs could easily discourage participants from taking the time needed to reflect on and really absorb the lessons inherent in their day-to-day experiences. In this context, it might help if they set learning goals. Seijts and Latham (2005), for example, found that in rapidly changing and ambiguous settings, participants who set specific and challenging learning goals consistently outperformed those who set equally specific and challenging output goals primarily because they took the time to seek out, process, and incrementally apply (i.e., experiment with) accumulating feedback. Another possible approach, popular with agile combat units in the U.S. Army, involves so-called "after-action reviews" (AARs) (Darling, Parry, and Moore, 2005). This process, notwithstanding its moniker, involves far more than venture postmortems. It encourages teams to use performance - calibrations and fluidity - to enhance learning by routinely allocating time at major transition points (e.g., when ventures move from exploration to exploitation, undergo key adaptations, and end) to hold no-holds-barred, what went right/what went wrong feedback sessions to capture key individual and collective learning (naturally avoiding finger-pointing and recriminations). AARs provide a double-whammy, enhancing both human and social capital simultaneously. 
It seems unlikely, however, that C-bAE participants can rely exclusively on developmental experiences that occur in the thick of things. One danger lies in the potential dilution of essential expertise in the form of core knowledge and skills as participants take on increasingly diverse assignments and challenges. To combat this, participants may choose to form communities of practice wherein those with common specialties and interests congregate (physically or virtually) to help each other stay on the leading edge (Cohen \& Prusak, 2001: 5380). Also, in the final analysis participants undoubtedly would find it essential to engage in a fair amount of individual learning on their own time, no doubt using Web-based or other forms of self-study programs.

\section{Rewards}

The CAS-based literature generally assumes that self-organizing is intrinsically motivating (Wheatley \& Kellner-Rogers, 1996). And indeed, self-organizing does provide C-bAE participants with all three of the core elements traditionally thought to enhance intrinsic motivation: (1) autonomy; (2) expansive, challenging, and meaningful work; and (3) plenty of feedback (Hackman \& Oldham, 1976). But, then, there is the unavoidable, although seldom addressed issue of pay. A pretty good case can be made that intrinsic motivation is potentially at risk if participants put too much emphasis on pay and especially on pay as an incentive (Kohn, 1993; Pfeffer, 1998). Perhaps, however, there are things that C-bAEs can do to minimize this risk.

One key issue pertains to process. No question, C-bAE participants decide how and how much they are paid, as well as issues having to do with policy and program designs. But this is pretty much wide open territory with few precedents. Table 1 illustrates one possibility. It describes an interesting experiment that occurred in one of AES Corporation's plants (Bakke, 2005: 125-6). Although employee participation, not self-organizing, was the norm here, pay plan participants still made the two most difficult decisions - how much money would be available for distribution and who got what. This kind of process has a number of important 
implications for C-bAEs. First, the inherent analyses, communication, and discussions help to embed knowledge about organizational realities, thus enhancing calibration. Second, the process helps to build social capital as everyone involved is required to consider the greater good over and above his or her own interests. And third, in the end the process provides a workable solution to one of the most vexing challenges C-bAEs are likely to face.

But what about broader policy and program decisions? Here we know of no precedents. C-bAEs probably have to offer high pay relative to prevailing market rates to compete for the kinds of talent they need. Certainly, this must be person-based pay since there are no fixed hierarchical levels or jobs. As indicated above, it is difficult to say whether or not incentives or merit pay should be offered. If the answer is yes, they probably should be based at least partly on firm performance using metrics that reinforce progress toward attaining shared purposes, as well as partly on individual contributions to venture or team performance (although attributions of credit are especially difficult when participants are frequently moving around see Axelrod \& Cohen [1999: 135-144]). Then there is the question of how much differentiation is too much. Too little may lead major contributors to feel underpaid and to withhold or withdraw their human capital, while too much could eat away at solidarity and reciprocity and thus destroy the social capital on which C-bAEs depend (Bottom, Holloway, Miller, Mislin \& Whitford, 2006). 
Table 1

Self-Managing Pay at AES Corporation

First, ... a group put together a plant budget that was consistent with [the] business plan. The budget had a line item for the total compensation expense ... They decided that the total compensation paid to everyone in the plant could not exceed the budgeted number. A task force ... had already researched comparable levels in the area ... That information was shared with everyone at the plant. Each individual was asked to propose his or her own salary for the year ahead and then to send the proposal to every other person in the plant for comment. After a weeklong comment period, each person made a decision about his or her own compensation. When the amounts were tallied, the sum exceeded the budget, but not by much. As it turned out, only one person had settled on a pay level substantially higher than others of comparable responsibility, skill level, and experience had. He was also one of the few who had not followed the advice of colleagues to adjust his pay. After he was given this information, he agreed to reduce his proposed salary, and the revised compensation total allowed the plant to meet its original budget.

The individuals who participated in this approach were changed by the process. They had a much better understanding of how compensation affected the overall economics of the organization. They learned the value of seeking advice when they had to balance competing interests. They put the interests of other stakeholders on a par with or even ahead of their own. The process pulled team members together and helped some make the transition from workers to business people... This method of setting compensation was stressful, successful, and fun. 


\section{Work Load}

In C-bAEs, the potential for overwork looms large. Participants control what they do and the allure of the work (i.e., the very same factors that enhance intrinsic motivation) can be highly seductive (Holwerda, 2006). It is easy for time poverty to become a status symbol, a signaling device to others that one is carrying her or his own weight, and then some. C-bAEs need harddriving participants, of course. But too much of a good thing is not necessarily a good thing. It can lead to burnout, high levels of dysfunctional stress, and emotional exhaustion (Dollard, Winefield, Winfield \& Jonge, 2000; Xie \& Johns, 1995), as well as to the loss of non-work identity (Rouseeau \& Arthur, 1999). How, then, do C-bAEs' participants keep from becoming their own worst enemies? This is another tough nut to crack. For one thing, there are great individual differences involved; workloads that are fine for some may be way over the top for others. Further, formal programs of the types tried in traditional organizations (on site child care, concierges, hair salons, and such, as well as part-time work, flex-time, and work at home) often simply serve as enablers of overwork or are rendered impotent by countervailing social pressures (Cohen \& Single, 2001). Perhaps the answer lies in a conscious attempt to instill some discipline on this score. Participants, for example, might establish shared operating norms that set limits on the appropriation of their human capital and attempt to reinforce them through extant social capital. Admittedly, though, this may be akin to hiring alcoholics to guard a liquor store. 


\section{Conclusion}

Clearly, the vast majority of firms competing in dynamic marketplaces are content to do so with spruced-up bureaucracies. This is understandable, even rational. But it is not the only possibility. Risk-takers looking to take a quantum leap ahead by adopting the next big thing in organizational paradigms might want to give the CAS-based approach a try. There are reasons to believe that C-bAEs may, in hypercompetitive situations, be better than traditional organizations at attaining series of temporary competitive advantages and thus at surviving over time. But, of course, at this juncture we cannot be sure of this. Despite a fair amount of research in natural settings and with computer simulations, we know very little about how the CAS-based approach is best operationalized within actual firms. So pioneers would have to make some giant leaps of faith.

Human resource researchers can help. The challenge, in a nutshell, is to ascertain whether and in what ways our traditional theories, concepts, and nostrums do and do not apply in C-bAEs - and where they are lacking, to propose new ones that might. Caution is in order though. Communities of scholars are CASs - interactive agents who by and large self-organize at the edge of chaos (i.e., under few, but some restraints) to form collaborations and engender novel and often coherent (and sometimes even salient) outcomes - new knowledge, lectures, articles, books, and such. Efforts to constrain the dynamics of this process or to pre-ordain its outcomes, especially in the present context, would constitute inappropriate attempts to undermine self-organizing and stifle emergence. Thus, all we dare do is offer a few tentative thoughts for human resource scholars to consider.

Potential data sources are scarce. One, of course, is previous research. Scholars of various stripes are applying complexity science concepts to organizational settings and, although few focus directly on human resource issues, their work is often tangentially suggestive (as we have tried to show here). Insights can also be gleaned from the experiences of quasi-C-bAE (i.e., firms exploring alternatives to traditional management approaches) such 
as Whole Foods, Gore-Tex, and Google (see Hamel, 2007: Chapters 4, 5, and 6), always keeping in mind that these observations are at best suggestive since, by definition, none of these firms has fully embraced the key tenets of complexity science (especially self-organizing). Scholars can also learn from experiments of their own making. Classroom simulations have provided us with useful insights, as the foregoing suggests and Langfred (2007) has recently demonstrated (using a sample of self-managed in teams in an MBA program). The analogy of detective work comes to mind; at this point, it seems, the research task is more a matter of piecing together clues obtained from various sources than of hoping to find the one killer app where everything falls into place. This, in turn, suggests the use of exploratory field studies and ad hoc and computer-based simulations over attempts to test predetermined hypotheses using tightly designed experiments or surveys. (Cause and effect hypotheses would seem to be incongruent with C-bAEs' holistic dynamics and inherent unpredictably anyway.)

So, what are we looking for? For starters, evidence of vertical alignments, keeping in mind that in C-bAEs this is a kinetic not static concept. Participants organize and strategize. Alignments occur when participants congregate and perform in ways that engender novel and coherent organizational forms and strategies (products, services, or solutions) that become competitive in their marketplaces. One potentially fruitful avenue of research, then, would be to identify or create situations where C-bAE participants succeed (or just as usefully do not succeed) in fostering vertical alignments and then attempting to uncover the factors that help (or hinder) their scalability (i.e., their abilities to assemble in and effectively utilize salutary selfconfigurations in timely, rapid, and reasonably uneventful ways) (Dyer \& Ericksen, 2007). Specifically, what are the factors that appear to facilitate (or inhibit) their calibrations - i.e., lines of sight - and/or their fluidity - i.e., flows and behavioral adjustments? Initially the analysis would focus on the patterns and dynamics of interactions among the participants involved, with particular attention being given to the ways in which these patterns and dynamics appear to be influenced by extant contextual conditions (e.g., the presence [or absence] of clearly shared 
purposes and social capital) and/or the collective characteristics of the participants themselves (e.g., high [or not so high] divergence on technical competencies and/or high [or not so high] convergence on cultural attributes). Further analysis might uncover how previous decisions by participants or by the simulation designers had fostered (or inhibited) the formation of shared purposes, social capital, mixes of competencies and attributes, and so forth and so on.

The purpose here is not to suggest how research ventures should flow, but rather to illustrate how they might unfurl. The aim is to entice a few human resource scholars into the realm of C-bAEs and thus incite useful discourses and interactions among them and with other complexity science scholars to the mutual benefit of both. As van Uden (2005: 64-65) points out:

On an ongoing basis, students of organization explore other disciplines, borrow ideas and concepts they believe can make a contribution of some kind, and try to fit these newly adopted ideas and concepts into existing research programmes. Concepts that prove successful in making a contribution ... become part of normal organizational discourse ... There is no reason to expect that students of organization will approach the science of complexity in a way that is fundamentally different ... does complexity science help us build competitively advanced firms or does it not? 


\section{References}

Anderson, P. (1999). Complexity Theory and Organization Science. Organization Science, 10, 3: $216-232$.

Argyris, C. \& Schon (1978). Organizational Learning: A Theory of Action Perspective. Reading, MA: Addison-Wesley.

Axelrod, R. and Cohen, M. (1999). Harnessing Complexity. New York: The Free Press.

Bakke, D. (2005). Joy at Work. Seattle, WA: PVG.

Baterman, T. \& Crant, J. (1993). The Proactive Component of Organizational Behaviour: A Measure and Correlates. Journal of Organizational Behaviour, 14: 103-118.

Becker, F. \& Sims, W. (2001). Offices that Work: Balancing Communications, Flexibility, and Cost. Ithaca, NY: Cornell University's International Workplace Studies Program.

Bennet, A. \& Bennet, D. (2004). Organizational Survival in the New Wortd: The Intelligent Complex Adaptive System. New York, NY: Elsevier.

Bottom, W., Holloway, J., Miller, G., Mislin, A. \& Whitford, A. (2006). Building a Pathway to Cooperation: Negotiation and Social Exchange Between Principal and Agent. Administrative Science Quarterty, 51, 1: 29-58.

Brockner, J., Konovsky, M., Cooper-Schneider, R., Folger, R., Martin, C., \& Bies, R. (1994). Interactive Effects of Procedural Justice and Outcome Negativity on Victims and Survivors of Job Loss. Academy of Management Journal, 37, 2: 398-409.

Brown, S. \& Eisehnardt, K. (1997). The Art of Continuous Change: Linking Complexity Theory and Time-Paced Evolution in Relentlessly Shifting Organizations. Administrative Science Quarterly, 42, 1: 1-35.

Carlisle, Y. \& McMillan, E. (2006). Guest Editors' Introduction. E:CO, 8, 1: vi-ix.

Chelariu, C., Johnston, W, \& Young (2002). Learning to Improvise, Improvising to Learn: A Process of Responding to Complex Environments. Journal of Business Research, 55: 141147.

Christensen, C. (1997). The Innovator's Dilemma. Boston, MA: Harvard Business School Press.

Cilliers, P. (2005). Knowing Complex Systems. In K. Richardson (ed.). Managing Organizational Complexity: Philosophy, Theory, Application. Greenwich, CT: Information Age Publishing: 7-20.

Cohen, D. \& Prusak, L. (2001). In Good Company. Boston, MA: Harvard Business School Press.

Cohen, J. \& Single, L. (2001). An Examination of the Perceived Impact of Flexible Work Arrangements on Professional Opportunities in Public Accounting. Journal of Business Ethics, 32: 317-328. 
Conlin, M. (2006). Square Feet: Oh, How Square! Business Week, July 3: 100-101.

Darling, M., Parry, C., \& Moore, J. (2005). Learning in the Thick of It. Hanard Business Review, July-August: 84-92.

DiRomualdo, T. \& Winter, J. (2005). Manifesto for the New Agile Workplace. Oxford, UK: Career Innovation Company.

Dollard, M., Winefield, H., Winfield, A. \& Jonge, J. (2000). Psychosocial Job Strain and Productivity in Human Service Workers: A Test of the Demand-Control-Support Model. Journal of Occupational and Organizational Psychology, 73: 501-510.

Dyer, L. \& Ericksen, J. (2007). Dynamic Organizations: Achieving Marketplace Agility Through Workforce Scalability. In J. Storey (ed.). Human Resource Management: A Critical Text ( $3^{\text {rd }}$ Edition). London: Thomson Learning.

Feldman, M. \& Pentland, B. (2003). Reconceptualizing Organizational Routines as a Source of Flexibility and Change. Administrative Science Quarterly, 48, 1: 94-118.

Foster, R. \& Kaplan, S. (2001). Creative Destruction: Why Companies that are Built to Last Underperform the Market and How to Transform Them. New York, NY: Currency.

Fradette, M. \& Michaud, S. (1998). Corporate Kinetics. New York: NY: Simon \& Schuster.

Frase-Blunt, M. (2003). A Recruiting Spigot. HR Magazine,48, 4: 70-79.

Fulmer, W. (2000). Shaping the Adaptive Organization. New York, NY: AMACOM.

Gershenson, C. \& Heylighen, F. (2005). How Can We Think Complex? In K. Richardson (ed.). Managing Organizational Complexity: Philosophy, Theory, Application. Greenwich, CT: Information Age Publishing: 47-62.

Gladwell, M. (2000). The Tipping Point. Boston, MA: Little, Brown and Company.

Godin, S. (2000). In the Face of Change, the Competent are Helpless. Fast Company, January-February: 230-234.

Hackman, J.. \& Oldham, G. (1976). Motivation Through the Design of Work. Organizational Behavior and Human Performance, 16: 250-279.

Haeckel, S. (1999). Adaptive Enterprises: Creating and Leading Sense-and-Respond Organizations. Boston, MA: Harvard Business School Press.

Hamel, G. (2006). Management a la Google. Wall Street Journal, August 26: A16.

Hamel, G. (2007). The Future of Management. Boston: Harvard Business School Press.

Hamel, G. \& Valikangas, L. (2003). The Quest for Resilience. Harvard Business Review, September: 52-63. 
Hazy, J., Goldstein, J. \& Lichtensteim, B. (2007). Complex System Leadership Theory. Mansfield, MA: ISCE Publishing.

Holbrook, M. (2003). Adventures in Complexity: An Essay on Dynamic Open Complex Adaptive Systems, Butterfly Effects, Self-organizing Order, Coevolution, the Ecological Perspective, Fitness Landscapes, Market Spaces, Emergent Beauty at the Edge of Chaos, and All that Jazz. Academy of Marketing Science Review, 2003, 6: 1-181.

Holwerda, J. (2006). Professional Work in the Agile Environment: Effects on Employees, the Organization, and Work Structures. Ithaca, NY: Unpublished Manuscript (36 pages).

Horn, J., Lovallo, D. \& Viguerie, S. (2006). Learning to Let Go; Making Better Exit Decisions. The McKinsey Quarterty, 2: 2-8.

Hoyt, D. \& Rao, H. (2006). Rite-Solutions: Mavericks Unleashing the Quiet Genius of Employees. Stanford, CA: Stanford Graduate School of Business Case HR-27.

Iannacci, F. (2005). Coordination Processes in Open Source Software Development: The Linux Case Study. E:CO, 7, 2: 21-31.

Joroff, M. \& Bell, M. (2001). The Agile Workplace: Supporting People and their Work. Boston, MA: Gartner.

Kao, J. (1996). Oticon(A). Boston, MA: Harvard Business School Case 9-395-155.

Kauffman, S. (1995). At Home in the Universe: The Search for Laws of Self-Organization and Complexity. New York, NY: Oxford University Press.

Kawai, T. (2005). The Imrovised-Orchestration Model of Organizational Evolution. In K. Richardson (ed.). Managing Organizational Complexity: Philosophy, Theory, Application. Greenwich, CT: Information Age Publishing: 313-330.

Kohn, A. (1993). Why Incentive Plans Cannot Work. Harvard Business Review, SeptemberOctober: 54-63.

Kurtz, C. \& Snowden, D. (2003). The New Dynamics of Strategy: Sensemaking in a complex and complicated world. IBM Systems Journal, 42, 3: 462-483.

Langfred, C. (2007). The Downside of Self-Management: A Longitudinal Study of the Effects of Conflict on Trust, Autonomy, and Task Interdependence in Self-Managing Teams. Academy of Management Journal, 50, 4: 885-900.

Leanna, C. \& van Buren, H. (1999). Organizational Social Capital and Employment Practices. Academy of Management Review, 24, 3: 538-555.

Lebaron, D. (1999). The Gurus Speak: Complexity and Organizations. Emergence, 1, 1: 73-91.

Lewin, A. \& Volberda (1999). Prolegomena on Co-Evolution: A Framework for Research on Strategy and New Organizational Forms. Organization Science, 10: 519-534.

Lewin, R. \& Regine, B. (2000). Weaving Complexity \& Business: Engaging the Soul at Work. New York, NY: Texere. 
Maguire, S. \& McKelvey, B (1999). Complexity and Management: Moving from Fad to Firm Foundations. Emergence, 1, 2: 19-61.

Matusik, S. \& Hill, C. (1998). The Utilization of Contingent Work, Knowledge Creation, and Competitive Advantage. Academy of Management Review, 23, 4: 680-697.

McFadyen, M. \& Cannella, A. (2004). Social Capital and Knowledge Creation: Diminishing Returns of the Number and Strength of Exchange Relationships. Academy of Management Joumal, 47, 5: 735-746.

McGrath, R. \& Boisot, M. (2005). Options Complexes: Going Beyond Real Options Reasoning. E:CO, 7, 2: 2-13.

McGrath, R. \& Keil, T. (2007). The Value Captor's Process: Getting the Most out of New Business Ventures. Harvard Business Review, May: 128-136.

Morgeson, F., Reider, M. \& Campion, M. (2005). Selecting Individuals in Team Settings: The Importance of Social Skills, Personality Characteristics, and Teamwork Knowledge. Personnel Psychology, 58, 3: 583-611.

Nahapiet, J. \& Ghoshal, S. (1998). Social Capital, Intellectual Capital, and the Organizational Advantage. Academy of Management Review, 23, 2: 242-266.

Naumann, S., Bies, R. \& Martin, C. (1995). The Roles of Organizational Support and Justice During Layoffs. Academy of Management Journal, 38, 1: 89-109.

Pascale, R., Millemann, M. \& Gioja, L. (2000). Surfing at the Edge of Chaos. New York, NY: Crown Business.

Peltoniemi, M. (2006). Preliminary Theoretical Framework for the Study of Business Ecosystems. E:CO, 8, 1: 10-19.

Peterson, R. \& Mannix, E. (2003). Leading and Managing People in the Dynamic Organization. Mahwah, NJ: Lawrence Erlbaum Associates.

Pfeffer, J. (1998). Six Dangerous Myths about Pay. Harvard Business Review, May-June: 109119.

Pisano, G. (1994). Knowledge, Integration, and the Locus of Learning: An Empirical Analysis of Process Development. Strategic Management Journal, Winter Special Issue 15: 85-100.

Prigogine, I. (1997). The End of Certainty: Time, Chaos and the New Laws of Nature. New York, NY: The Free Press.

Richardson, K. (2005). To Be or Not To Be? That is NOT the question: Complexity Theory and the Need for Critical Thinking. In K. Richardson (ed.). Managing Organizational Complexity: Philosophy, Theory, Application. Greenwich, CT: Information Age Press: 21-46.

Rousseau, D. \& Arthur, M. (1999). The Boundaryless Human Resource Function: Building Agency and Community in the New Economic Era. Organizational Dynamics, Spring: 7-18. 
Seijts, G. \& Latham, G. (2005). Learning versus Performance Goals: When Should Each be Used? Academy of Management Executive, 19, 1: 124-131.

Sherehiy, B., Karwowski, W., \& Layer, J. (2007). A Review of Enterprise Agility: Concepts, Frameworks, and Attributes. International Joumal of Industrial Ergonomics, 37: 445-460.

Snowden, D. (2006). Stories from the Frontier. E:CO, 8, 1: 85-88.

Stacey, R. (1996). Complexity and Creativity in Organizations. San Francisco: Berrett-Koehler Publishers.

Stacey, R., Griffin, D. \& Shaw, P. (2000). Complexity and Management: Fad or Radical Challenge to Systems Thinking? London, UK: Routledge.

Stewart, T. (2007). Making a Difference. Harvard Business Review, March: 14.

Surowiecki, J. (2004). The Wisdom of Crowds. New York, NY: Doubleday.

Tapscott, D. \& Williams, A. (2006). Wikinomics: How Mass Collaboration Changes Everything. New York, NY: Penguin Group.

Ulrich, D. \& Lake, D. (1990). Organizational Capability: Competing from the Inside Out. New York, NY: Wiley.

Van Uden, J. (2005). Using Complexity Science in Organization Studies: A Case for Loose Application. E:CO, 7, 1:60-66.

Wheatley, M. \& Kellner-Rogers (1996). A Simpler Way. San Francisco, CA: Berrett-Koehler Publishers.

Wright, P. \& Snell, S. (1998). Toward a Unifying Framework for Exploring Fit and Flexibility in Strategic Human Resource Management. Academy of Management Review, 23, 4: 756772.

Xie, J. \& Johns, G. (1995). Job Scope and Stress: Can Job Scope be too High? Academy of Management Journal, 38, 5: 1288-1309. 